\title{
Public Health and Economic Importance of Bovine Brucellosis: An Overview
}

\author{
Mahendra Pal $^{1, *}$, Fikru Gizaw ${ }^{2}$, Gelane Fekadu$^{2}$, Gezahagn Alemayehu$^{2}$, Venkataramana Kandi $^{3}$ \\ ${ }^{1}$ Narayan Consultancy of Veterinary Public Health and Microbiology, 4, Aangan-I, Jagnath Ganesh Dairy Road, Anand-388001, India \\ ${ }^{2}$ College of Veterinary Medicine, Samara University, P.B. Box No.132, Samara, Ethiopia \\ ${ }^{3}$ Department of Microbiology, Prathima Institute of Medical Sciences, Nagunur, Karimnagar, India \\ *Corresponding author: palmahendra2@gmail.com, ramana_20021@rediffmail.com
}

\begin{abstract}
Brucellosis is an important infectious re-emerging bacterial zoonosis of public health and economic significance. It affects the health and productivity of livestock as well as that of their owners and can have a deep economic impact. Brucellosis in cattle is usually caused by bio-vars of Brucella abortus. In some countries, particularly in southern Europe and western Asia, where cattle are kept in close association with sheep or goats, infection can also be caused by $B$. melitensis. Occasionally, $B$ suis may cause a chronic infection in the mammary gland of cattle, but it has not been reported to cause abortion or spread to other animals. Humans are almost exclusively exposed to brucellosis through contact with animals and food of animal origin, transmitted via human contact with secretions, predominantly through calving and abortions. The disease can also be spread through the consumption of contaminated, unpasteurized dairy products. Globally, 500000 cases of human brucellosis are reported annually. The prevalence of human brucellosis differs between areas and has been reported to vary with standards of personal and environmental hygiene, animal husbandry practices, and species of the causative agent and local methods of food processing. The most common signs and symptoms of human brucellosis are fever, asthenia, myalgia, arthralgia, sweats, lymphadenopathy, hepatomegaly and splenomegaly. Endemic brucellosis in low-income countries of sub-Saharan Africa and South Asia has multiple economic implications across agriculture and public health and broader socio-economic development sectors. It is an economically important disease of livestock causing reproductive wastage through infertility, delayed heat, loss of calves, reduced meat and milk production, culling and economic losses. Microscopic examination of stained smears can be useful for a presumptive diagnosis, particularly if the direct examination supported by other tests. Mass vaccination is the mainstay of brucellosis control in livestock, but should be combined with other measures that limit the spread of the pathogen, allow identification of animals and herds, and increase community participation. Human brucellosis is usually prevented by controlling the infection in animals; Pasteurization of dairy products is an important safety measure where this disease is endemic.
\end{abstract}

Keywords: animal, brucellosis, epidemiology, public health, zoonosis

Cite This Article: Mahendra Pal, Fikru Gizaw, Gelane Fekadu, Gezahagn Alemayehu, and Venkataramana Kandi, "Public Health and Economic Importance of Bovine Brucellosis: An Overview." American Journal of Epidemiology and Infectious Disease, vol. 5, no. 2 (2017): 27-34. doi: 10.12691/ajeid-5-2-2.

\section{Introduction}

Since the earliest days of civilization, man is closely associated with animals and thus gave an opportunity of inter communicability of microbial infections between humans and animals [1]. There are many diseases of cattle, which are transmitted to humans [1]. Among these, brucellosis (Bang's disease, Contagious abortion, Malta fever, Undulant fever) is a highly infectious disease of humans and animals, which has been reported from many countries of the world including Ethiopia and India [1,2,3]. The disease is caused by Gram-negative, facultative intracellular bacteria that can infect many species of animals [1]. Brucellosis in cattle is usually caused by biovars of Brucella abortus. In some countries, particularly in southern Europe and western Asia, where cattle are kept in close association with sheep or goats, infection can also be caused by $B$ melitensis [4]. Occasionally, Bsuis may cause a chronic infection in the mammary gland of cattle, but it has not been reported to cause abortion or spread to other animals [5].

Brucella mainly affects cattle, sheep, goats, camels and pigs, as well as causing disease in humans [1]. Cattle (Bos Taurus) are natural hosts of Brucella abortus, Humans are susceptible to both $B$ abortus and $B$ melitensis, the latter being most frequently reported in humans [6].

The World Health Organization (WHO) estimates that a quarter of human cases go unreported, yet half a million cases per year are recorded [7]. Humans are almost exclusively exposed to brucellosis through contact with animals and food of animal origin or transmitted via human contact with secretions, predominantly through calving and abortions, this disease can also be spread through the consumption of contaminated, unpasteurized dairy products. Characterized by febrile illness in humans, the disease is often difficult to diagnose solely from the 
clinical picture, due to its similarities to other febrile diseases, such as malaria or typhoid. Brucellosis is endemic in many countries, and is responsible for a considerable economic and health burden [8].

It is an economically important disease of livestock causing reproductive wastage through infertility, delayed heat, loss of calves, reduced meat and milk production, culling and economic losses from international trade bans [9]. Brucellosis can be diagnosed directly by polymerase chain reaction (PCR), isolation (culture) of the bacteria, and indirectly by antibody detection either in serum or milk $[1,6]$.

In many endemic areas, uncontrolled animal movement and lack of veterinary infrastructure are major obstacles to disease control. Brucellosis is persisting in pastoral areas of the world, despite various control efforts [10]. While diagnosis, surveillance, and management may be generally well understood in many countries, brucellosis remains largely under-diagnosed and uncontrolled amongst many pastoral peoples and small-scale livestock holders. Lack of resources combined with difficulty in local diagnosis, limited knowledge of regional epidemiology, and little understanding of the social factors contributing to disease may underpin persistence of brucellosis in pastoral ecosystems $[10,11]$. The objective of this paper is to present an overview on the public health and economic significance of bovine brucellosis.

\section{Literature Review}

\subsection{Etiology}

Brucellae are Gram-negative, facultative intracellular bacteria that can infect many species of animals, including humans. Ten species are recognized within the genus Brucella. There are six 'classical' species, $B$ abortus, $B$ melitensis, $B$ suis, $B$ ovis, $B$ canis and $B$ neotomae, and another four species have been recognized more recently $[12,13]$.

The species of Brucella and their principal animal hosts are Brucella abortus (cattle) Brucella melitensis (goat), Brucella suis (pig) and Brucella ovis (sheep) [14].

Non-bovine animals, and humans, can also contract the disease, which in turn play a significant role in its persistence and transmission. Brucella abortus infecting cattle has seven recognized biovars, the most reported of which are biovars $1,2,3,4$, and 9 , with biovar 1 being the most prevalent in Latin America. The distribution of biovars could be important in ascertaining the source of some infections $[15,16]$.

\subsection{Pathogenesis}

Brucella species are facultative intracellular pathogens and establish infection by invading macrophages and evading macrophage-induced host protection mechanisms $[17,18]$. These characteristics contribute to clinical signs and therapeutic considerations, including the difficulty in both diagnosis and treatment. Following exposure in humans, the organisms travel along the lymphatic pathways; focal disease is most commonly identified in the reticulo-endothelial tissues such as the liver and spleen.
In chronic infections, organisms typically localize in joints, especially large joints such as the sacroiliac or lumbar vertebral joints. Pulmonary disease is a less common form of brucellosis $[19,20]$.

\subsection{Epidemiology}

\subsubsection{Geographical Distribution in Animal}

Brucellosis has worldwide distribution, but nowadays the disease is rare in the United States of America (USA) and in many other industrialized/developed nations because of routine screening of domestic livestock and animal vaccination programs. This disease, however, is a leading cause of zoonotic infections in the countries of the Eastern Mediterranean Region and a disease of economic importance [21].

Brucella abortus is found worldwide in cattle-raising regions, except in Japan, Canada, and some European countries. Australia, New Zealand, and Israel are among few countries where it has been eradicated. Eradication of disease from domesticated herds is nearly complete in the USA. B abortus can be found in wildlife hosts in some regions, including the Greater Yellowstone Area of North America [22].

There have been reports of cows infected with $B$ abortus that test seronegative. Brucella abortus was isolated in119 milk samples from seronegative cows and the isolates belonged to biovars 2, 3, and 9. In Mexico, the field strain of $B$ abortus with a smooth phenotype was reported to have been isolated from the vaginal exudates of two cows, vaccinated with reduced-dose RB51, which had calved normally and were seronegative [23].

Bovine brucellosis is one of the infectious diseases and has been reported from several parts of Ethiopia, the seroprevalence of bovine brucellosis in cattle is under traditional extensive husbandry [24]. In Borena zone of oromia region, the highest seroprevalence (50\%) was documented using ELISA [25].

\subsubsection{Occurrence of Disease in Animals}

In Jordan, the highest prevalence of brucellosis was found in cattle and sheep [26]. Results of a study reported from north-western state of India called juban, which included milk samples from 345 randomly selected animals, when analyzed with ELISA, revealed prevalence of $20.67 \%$ and $16.41 \%$ in cattle and buffaloes, respectively. The overall apparent prevalence of brucellosis was noted to be $18.26 \%$. Given the sensitivity and specificity of ELISA at $100 \%$ and $99.3 \%$, respectively, true prevalence was calculated to be $17.68 \%$ [27].

In global terms, the majority of human and animal brucellosis is found in sub-Saharan Africa with large pastoral communities has been recorded at herd level, within-herd level and individual animal level .The persistent disease was observed in most countries in the Sahel, with Ethiopia, Chad, Tanzania, Nigeria, Uganda, Kenya, Zimbabwe and Somalia reporting brucellosis in humans attributed to domestic cattle, camels, goats and sheep calculated an estimated 22seroprevalence of $16.2 \%$ with in cattle in sub-Saharan African [28].

In Ethiopia, most research done on brucellosis has been focused on intensive dairy cattle herds in urban and peri- 
urban areas. In 1987, the World Organization for Animal Health (OIE) reported a prevalence of 20\%; the prevalence was higher around large towns than in rural areas [29]. Since the first report of brucellosis in the 1970's in Ethiopia, the disease has been noted as one of the important livestock diseases in the country [30,31]. A large number of articles have been published reporting individual seroprevalence ranging from $1.1 \%$ to $22.6 \%$ in intensive management systems [32] and $0.1-15.2 \%$ in extensive management system [24,33,34]. In zebu cattle of the central highlands, a prevalence of $4.2 \%$ was reported [35]. Another study from Addis Ababa, Ethiopia found a prevalence of $10 \%$ [36]. A study conducted on smallholder farmers of central Ethiopia (Wuchale Jida district) reported a prevalence rate of $11 \%$ [31].

In cattle under extensive management systems, studies conducted in different regions of Ethiopia between 2003 and 2005 reported individual-level prevalence rates of $0.8 \%$ and $3.2 \%$ and herd-level prevalence of $2.9 \%$ and 42.3\%respectively [37]. The overall seroprevalence of bovine brucellosis in pastoral and agro pastoral regions of East Showa Zone, Oromia Regional State, was $11.2 \%$ by the Rose Bengal Plate Test (RBPT). This report was within the range 10 to $15 \%$ that was estimated for any assumed brucellosis seroprevalence for East Africa [38].

According to study of bovine Brucellosis in cattle under traditional production system in North- West Ethiopia Benishangul-gumuz, among the 1,152 cattle screened for $B$ abortus antibodies, 14 (1.2\%) tested positive by RBPT. Of these, 11 animals (79 \%;) were confirmed positive by complement fixation test (CFT), giving an apparent seroprevalence of $1.0 \%$ in the study area [39,40].

\subsubsection{Source of Infection and Mode of Transmission in Animals}

The animal infection is transmitted through ingestion or inhalation of organisms that are present in fetal fluids or other birth products. In the Herd animals, the infection can be due to introduction of an infected animal that subsequently gives birth or aborts a fetus, whereupon pasture or water becomes contaminated by these excretions. Transient disease such as abortion can also develop following administration of a live Brucella vaccine, particularly the $B$ abortus vaccine strain 19 . Among dogs and sheep, transmission of rough strains of Brucella may be more common via the venereal route, although supporting data are limited. The organisms have been recovered from fetal and manure samples that remained in a cool environment for longer than 2 months. However, exposure to sunlight kills the bacterium within a few hours, and the organism is susceptible to many common disinfectants [41].

\subsection{Clinical Signs in Animals}

The incubation period varies between 14 and 120 days [42]. Primary clinical manifestations of brucellosis among livestock are related to the reproductive tract. In highly susceptible non-vaccinated pregnant cattle, abortion after the $5^{\text {th }}$ month of pregnancy is cardinal feature of the disease [14]. Retention of placenta and metritis are common sequels to abortion [43]. Females usually abort only once, presumably due to acquired immunity. In general, abortion with retention of the placenta and the resultant metritis may cause prolonged calving interval and permanent infertility.

In cattle, $B$ abortus causes abortions, stillbirths and weak calves. The placenta may be retained and lactation may be decreased. Epididymitis, seminal vesiculitis, orchitis and testicular abscesses are sometimes seen in bulls. Infertility occurs occasionally in both sexes, due to metritis or orchitis/epididymitis. Hygromas, particularly on the leg joints, are a common symptom in some tropical countries. Arthritis can develop after long-term infections. Systemic signs do not usually occur in uncomplicated infections, and deaths are rare except in the fetus or newborn. Infections in non-pregnant females are usually asymptomatic, but pregnant adult females infected with $B$ abortus develop placentitis, which normally causes abortion between the fifth and ninth month of pregnancy. Even in the absence of abortion, there is heavy shedding of bacteria through the placenta, fetal fluids and vaginal exudates. The mammary gland and regional lymph nodes can also be infected and bacteria can be excreted in milk [44].

\subsection{Diagnosis}

\subsubsection{Microscopic Examination}

Microscopic examination of stained smears can be useful for a presumptive diagnosis, particularly if the direct examination supported by other tests occasionally, bacteria can be recovered from the cerebrospinal fluid, urine or tissues. Brucella spp. can be isolated on a variety of plain media, or selective media such as Farrell's medium. Brucella abortus is highly infectious to humans and therefore, samples should be collected and handled with all appropriate precautions. A variety of samples can be collected for culture and microscopic examination. Milk samples and vaginal swabs are particularly useful for diagnosis in live cows. Milk samples for culture should contain milk from all four quarters. In addition, Babortus can often be isolated from the secretions of non-lactating udders. This organism can also be cultured from aborted fetuses (stomach contents, spleen and lung) or the placenta [22].

\subsubsection{Serological Tests}

Several commercial serological tests are available for humans and animals [6]. The Rose Bengal test (RBT) has been recommended as a suitable screening test at the national or local level for diagnosis of brucellosis in animals [6]; enzyme-linked immunoassays (ELISA) and the fluorescent polarization assay (FPA) have recently been added as prescribed tests. They are simple, but robust, tests which can be conducted with a minimum of equipment and are therefore also suitable for smaller laboratories. Further serological tests (e.g. the Combs' test, the serum or plate agglutination test and the immunecapture test) are available, and have specific advantages and disadvantages [45].

\subsubsection{Milk Ring Test (MRT)}

The MRT has been explained as a satisfactory and inexpensive test for the surveillance of dairy herds for 
brucellosis. The MRT is easy, simple and takes low time to perform [14]. When positive test result is obtained, all animals contributing milk should be tested for seroprevalence. It detects lacteal anti Brucella IgM and IgA bound to milk fat globules (OIE, 2004). Milk that contains low concentration of lacteal IgM and IgA or that lacks the fat-clustering factors can give false negative results. Because lacteal antibodies rapidly decline after abortion or parturition, MRT, using $1 \mathrm{ml}$ milk, to detect Brucella antibodies in individual animal or in tank milk is strongly discouraged. In large herds $(>100$ lactating animals), the sensitivity of the test becomes less reliable [14]. False positive reactions may also occur in animals vaccinated 4 months prior to testing and in samples containing abnormal milk (colostrum) or in case of mastitis [46].

\subsubsection{Polymerase Chain Reaction}

Polymerase chain reaction (PCR) assays can be used to detect BrucellaDNA in pure cultures and in clinical specimens, i.e. serum, whole-blood and urine samples, various tissues, cerebrospinal, synovial or pleural fluid, and pus [47]. Direct detection of Brucella DNA in brucellosis patients is a challenge because of the small number of bacteria present in clinical samples and inhibitory effects arising from matrix components. Basic sample preparation methods should minimize inhibitory effects and concentrate the bacterial DNA template [48].

\subsection{Treatment}

Despite extensive studies over the past 15 years, the optimum antibiotic therapy for brucellosis is still disputed. The treatment recommended by the World Health Organization for acute brucellosis in adults is rifampicin 600 to $900 \mathrm{mg}$ and doxycycline $200 \mathrm{mg}$ daily for a minimum of 6 weeks; some still claim that the long-established combination of intramuscular streptomycin with an oral tetracycline gives fewer relapses [49]. Antibiotics are usually the mainstay of treatment; long-term treatment may be required. Some forms of localized disease, such as endocarditis, may require surgery [50].

\subsection{Prevention and Control}

Mass vaccination is the mainstay of brucellosis control in livestock, but should be combined with other measures that limit the spread of the pathogen, allow identification of animals and herds, and increase community participation [51].

Mass vaccination of livestock against brucellosis in Mongolia was noted to be cost effective and resulted in net economic benefit, if interventions costs were shared between the different beneficiaries based on an inter sectorial economic assessment. The presented transsectorial analysis is applicable to other zoonoses and environmental threats to public health and contributes to the perception that interventions in the livestock sector can control disease transmission to humans [52].

In Ethiopia as the source of human brucellosis is direct or indirect exposure to infected animals or their products, prevention must focus on various strategies that will mitigate infection risks. To our knowledge, there have been no national programs proposed for prevention and control of brucellosis in Ethiopia. Similarly, at regional levels, no strategy is in place to control brucellosis. This is largely a result of lack of facilities and budget to run such a program. Moreover, many responsible bodies may not recognize the significance of brucellosis given the contradictory and sometimes low prevalence data. However, now, it is crucial to define geographical extent of the problem and then allocate resources and funds to initiate prevention and control strategies in Ethiopia and other countries with similar economic situations [53].

\subsubsection{Classification of Endemic Areas Based on Prevalence}

Classification of endemic areas based on prevalence will enable initiation of appropriate control methods in endemic areas. Identification of low and high prevalence areas will greatly facilitate the implementation of appropriate control programs, and should ideally be combined with other strategies like accurate livestock census data and a livestock identification system (either simple ear notches or more sophisticated ear labeling system). Vaccine storage and quality control systems are also a priority coupled with surveillance systems and postvaccination surveillance to identify the remaining foci of infection (the efficacy of post-vaccination surveillance is reliant upon existing records combined with reliable livestock identification). In areas where the disease is less prevalent (for example livestock seroprevalence of less than $1 \%$ ), cull policy with compensation may be recommend. For areas with high and moderate prevalence (>5\%) under well-organized farming systems, we may recommend test and segregation policy by which animals with brucellosis will be isolated and products consumed after pasteurization, with animals being disposed of properly at the end of their productive live [53].

\subsubsection{Characterization of Brucella Species}

One of the most successful methods for prevention and control of livestock brucellosis is through vaccination. In different parts of the world both live vaccines, such as Babortus S-19, B melitensis Rev-1, Bsuis S-2, rough Bmelitensis strain M111, and B abortus strain RB-51 and killed vaccines, such as $B$ abortus $45 / 20$ and $B$ melitensis $\mathrm{H}-38$ are available. Each vaccine has been reported to have its own advantages and disadvantages [54], with protection following localized persistence of live vaccines preferred by most and showing efficacy in small ruminants [55,56] and cattle [57]. Use of the RB-51 attenuated live vaccine has recently gained popularity for control of brucellosis in cattle [57], but on a cautionary note, the failure of this strain to induce serological reactivity, coupled with its inherent resistance to rifampicin, might complicate detection and management of zoonotic infection spilling into humans with occupational risk factors for acquiring brucellosis. Currently, despite huge research efforts, no vaccine has been approved for the prevention of human brucellosis. Treatment regimens for human brucellosis require combination of antibiotics. These have recently been compared using meta-analysis [58]. Currently, vaccination against animal brucellosis has yet to be explored in Ethiopia. As a prerequisite, Brucellas species identification 
should be undertaken to inform selection of the most appropriate vaccine (for example, $B$ melitensis has recently been found infecting cattle in Kenya) [59] and to enable differentiation of vaccine and wild-type strains.

\subsubsection{Vaccination}

Vaccination is generally recommended for seroprevalence rates between 2 and $10 \%$. Whether a strategy of test and segregation alone for high seroprevalence rates is sufficient may depend on the farming conditions. This might be appropriate for farms in conjunction with appropriate hygienic measures, but supplementation with vaccination may be required to control the disease in extensive livestock conditions. Application of farm bio-safety measures: Implementation of measures to reduce the risk of infection through personal hygiene, adoption of safe working practices, protection of the environment and food hygiene should minimize risks of further infection. Under appropriate conditions, Brucella organisms can survive in the environment for prolonged periods. Their ability to withstand inactivation under natural conditions is relatively high compared with most other groups of non-sporing pathogenic bacteria [60].

\subsubsection{Pasteurization}

Brucella abortus is inactivated by pasteurization and its survival outside the host is largely dependent on environmental conditions. The pathogen may survive in aborted fetus in the shade for up to eight months, for two to three months in wet soil, one to two months in dry soil, three to four months in feces, and eight months in liquid manure tanks. For example, in nomadic populations where people travel in search of green pasture and water, the proper handling and burying of abortion materials to prevent contamination of water sources and pasture is of paramount importance. Furthermore, the common practice of feeding abortion materials to dogs should be avoided as this increases the risk of transmission to other animals. It is imperative to education on risks for infection to these populations to influence behavioral practices that will reduce risks of transmission [43].

Bacterial survival is prolonged at low temperatures and organisms will remain viable for many years in frozen carcass. The organisms in aqueous suspensions are readily killed by most disinfectants. A $10 \mathrm{~g} / \mathrm{l}$ solution of phenol will kill Brucella in water after less than 15 min exposure at $37^{\circ} \mathrm{C}$. Formaldehyde solution is the most effective of the commonly available disinfectants, provided that the ambient temperature is above $15^{\circ} \mathrm{C}$. The development of a national veterinary extension services in the country, is essential to promote awareness about brucellosis, its impact on livestock production and zoonotic risks, would provide a valuable prevention measure. This would help to unify both community/dairy cattle producers to control and eliminate brucellosis. Currently, many dairy cattle producers hide or dispose of animals with a history of abortion, potentially facilitating disease transmission between farms and regions. This seriously undermines efforts of controlling and preventing the disease [60].

Human brucellosis is usually prevented by controlling the infection in animals. Pasteurization of dairy products is an important safety measure where this disease is endemic. Unpasteurized dairy products and raw or undercooked animal products (including bone marrow) should not be consumed. Good hygiene and protective clothing/equipment are very important in preventing occupational exposure. Precautions should be taken to avoid contamination of the skin, as well as inhalation or accidental ingestion of organisms when assisting at a birth, performing a necropsy, or butchering an animal for consumption. Care should be taken when handling an aborted fetus or its membranes and fluids. Risky agricultural practices such as crushing the umbilical cord of newborn livestock with the teeth or skinning aborted fetuses should be avoided. The Strain 19 B abortus vaccine and $B$ melitensis Rev-1 vaccine must be handled with caution to avoid accidental injection or exposure. Adverse events have also been reported with the $B$ abortus RB-51 vaccine, although it is safer than Strain 19. Persistent infections with vaccine strains have occasionally been reported in vaccinated animals. These strains can be shed in the milk or aborted [22]. The greatest risk is most likely the introduction of infected animals through migration or trade from neighboring nonvaccinated areas or countries, Unless strict measures can be taken to control trade and prevent introduction of potentially infected animals, it will be necessary to continue vaccinating susceptible animals, to minimize the risk of reintroduction from neighboring unvaccinated areas a region-wide approach would be more beneficial, Equally important to a well-designed control programs the presence of an effective surveillance system [61].

\section{Public Health Importance of the Disease}

Brucella abortus, $B$ melitensis and $B$ suis are highly pathogenic for humans [62]. Brucellosis remains the most common zoonotic disease in the world, with more than 500,000 new cases reported annually [63]; the actual number of cases, including undetected and unreported cases, is believed to be considerably higher [64]. Brucellosis is often a neglected disease despite being endemic with high zoonotic potential in many countries [65]. The prevalence of human brucellosis differs between areas and has been reported to vary with standards of personal and environmental hygiene, animal husbandry practices, and species of the causative agent and local methods of food processing [66].

The Brucellosis 2003 International Research Conference estimated that 500,000 human infections occur per year worldwide, with incidences ranging from less than one case per 100,000 population in UK, USA and Australia, through 20 to 30 cases per 100,000 in southern European countries such as Greece and Spain, to more than 70 cases per 100,000 in Middle Eastern States such as Kuwait and Saudi Arabia [67, 68]. The majority of reported human brucellosis cases are caused by $B$ melitensis, $B$ abortus, and $B$ suis, in occurrence order, novel and atypical Brucella are also being investigated [64].

As compared to study of animal brucellosis, study of human brucellosis in Ethiopia is sparse with even less information on risk factors for human infection. For instance, out of 56 cases with fever of unknown origin, 
two (3.6\%) were reported to be positive for B. abortus antibodies by RBPT and CFT [69]. A study conducted in traditional pastoral communities by Ragassa and others [70] using Babortus antigen revealed that $34.1 \%$ patients with febrile illness from Borena, 29.4\% patients from Hammer, and 3\% patients from Metema areas were tested positive using Brucella IgM/IgG lateral flow assay. Studies conducted in high risk group such as farmers, veterinary professionals, meat inspectors and artificial insemination technicians in Amhara Regional State [71], Sidama Zone of Southern People Nations and Nationalities Sate [72], and Addis Ababa [73] found a seroprevalence of $5.30 \%, 3.78 \%$ and $4.8 \%$ by screening sera from 238, 38 and 336 individuals respectively. The discrepancy between and others might be due to difference in milk consumption habits and sensitivity of test methods used [70].

Humans may become infected by ingestion of unpasteurized cheese or milk, by direct transmission through contact with infected animals or by handling specimens containing Brucella spp. in laboratory. It also transmitted to human by the consumption of raw dairy products and by direct contact with the skin or mucosa during parturition and abortion. Cattle are natural hosts for Brucella abortus, and sheep (Ovis aries) and goats (Capra hircus) for $B$ melitensis and $B$ ovis, respectively. Humans are susceptible to both $B$ abortus and $B$ melitensis, the latter being most frequently reported in humans [6].

The most common signs and symptoms of human brucellosis are fever, asthenia, myalgia, arthralgia, sweats, lymphadenopathy, hepatomegaly and splenomegaly [1]. Oste-oarticular manifestations (peripheral arthritis, sacroiliitis, spondylitis) are the most common forms of localized disease [74].

\section{Economic Importance}

Endemic brucellosis in low-income countries of subSaharan Africa and South Asia has multiple economic implications across agriculture and public health and broader socio-economic development sectors. Efforts to control the disease in low-income countries must take a different approach. Simply replicating past successes in brucellosis control and eradication in high-income countries will not work. Low-income countries have at least a ten-fold higher burden of infectious disease from a wide variety of pathogens [75].

The assessment of the economic aspects of brucellosis, with emphasis on the low-income countries of Africa and Asia, is structured in three main parts. The first describes an overall framework for economic assessment of disease burdens and the impacts of potential control programs. The second part systematically reviews available animal, human and joint burden estimates from studies conducted in these regions. The third section provides estimates, when available, of different costs associated with brucellosis illness and its control. This section also comments on tools and approaches for assessing control programs that are of relevance to low and middle-income [76,77].

When brucellosis is detected in a herd, flock, region, or country, international veterinary regulations impose restrictions on animal movements and trade, which result in huge economic losses. The economic losses as well as its zoonotic importance are the reasons whyprograms to control or eradicate brucellosis in cattle [46].

In Ethiopia, information on losses specifically through brucellosis in the different types of production systems is sparse, except for Tariku (1994) who reported an annual loss from brucellosis estimated to be 88,941.96 Ethiopian Birr (\$5231 equivalent) among 193 cattle, largely due to reduced milk production and abortions (Chaffa State Farm, Wollo, from 1987 to 1993).

\section{Conclusions and Recommendations}

Brucellosis is a bacterial disease which has both public health and economic importance. This disease can be transmitted from infected animal to healthy one through fetal discharges, contaminated feed and water, licking of vaginal discharges or secretions or newly born infected calves in animals. In human, brucellosis can be transmitted via consumption of unpasteurized milk and cheese, direct contact with infected animal and handling of specimen that contaminated with Brucella species. Brucellosis is a worldwide disease both in developed and developing country even though; this disease is eradicated in developed countries with vaccination program and screening method of livestock, yet this disease poses serious problem in developing countries mainly African countries including Ethiopia. This disease causes abortion, delayed heat, loss of calve, infertility, reduce milk production and meat production and still birth in cattle due to absence of regular screening method and vaccination programs in most developing country mostly in sub Saharan Africa. Since brucellosis is a leading zoonotic bacterial disease that affects human health and economy due to trade ban attention must be given to control or prevent this disease in developing country through routinely screening method, regular vaccination and tackling the mode of transmission of this disease may reduce risk posed by this disease. In addition, at regional, national and international level strict regulation should be devised to control or prevent as well as to eradicate this disease.

Therefore, we recommend implementation of control and prevention measures of brucellosis in animals, to stop human infections. Good hygiene and protective clothing/equipment are very important in preventing occupational exposure. In Ethiopia and elsewhere in endemic regions, in addition to the epidemiological investigations, vaccine trial studies and effective control and prevention strategies should be formulated and applied. Even though brucellosis is eradicated in some developed countries, much work needs to be still done in developing countries including Ethiopia to eradicate brucellosis.

\section{References}

[1] Pal, M. (2007). Zoonoses. $2^{\text {nd }}$ Ed. Satyam Publishers, Jaipur, Ethiopia.

[2] Pal, M. and Jain, H.S. (1986). Anthropozoonotic role of Brucella abortus. International Journal of Zoonoses 13: 246-248. 
[3] Hadush, A., Pal, M., Kassa, T. and Zeru, F. (2013). Seroepidemiology of camel brucellosis in the afar region of Northwest Ethiopia. Journal of Veterinary Medicine and Animal Health 5: 269-275.

[4] Jimenez De Bagues, M.P., Marin C. and Blasco J.M. (1991).Effect of antibiotic therapy and strain 19 vaccination on the spread of Brucella melitensis within an infected dairy herd. Prev. Vet. Med., 11, 17-24.

[5] Ewalt, D.R., Payeur J.B., Rhyan, J. C. and Geer P.L., (1997). Brucella suis biovar 1 in naturally infected cattle: a bacteriological, serological, and histological study. J. Vet. Diagn. Invest, 10: 417-420.

[6] Food and Agriculture Organization of the United Nations, World organization for Animal Health \& Word Health Organization (WHO) (2006). Brucellosis in humans and animals. Principle author: M.J. Corbel. WHO, Geneva.

[7] World Health Organization (WHO) (2006). Brucellosis in humans and animals. WHO, Geneva iculum.Curr.Opin.Microbiol.7: 93-97.

[8] Roth, F., Zinsstag, J., Orkhon, D., Chimed-Ochir, G.,Hutton, G., Cosivi O., Carrin, G. and Otte, J. (2003). - Human health benefits from livestock vaccination for brucellosis. Case study. Bull. WHO, 81: 867-876.

[9] McDermot,t J.J. and Arimi, S.M. (2002). Brucellosis in subSaharan Africa: epidemiology, control and impact. Vet. Microbial, 90: 111-134.

[10] McGiven, J.A. (2013). New developments in the immunodiagnosis of brucellosis in livestock and wildlife. In Brucellosis: rec. dev. towards One Hlth, 32: 163-176.

[11] Racloz, V, Schelling, E, Chitnis N, Roth F, and Zinsstag, J. (2013). Persistence of brucellosis in pastoral systems. Rev Sci Tech. 32: 61-70.

[12] Corbel, M.J., and Banai, M., (2005). Genus, I.,Brucella Meyer and Shaw 1920, 173AL. In, Brenner DJ, Krieg NR, Staley JT (Eds). Berger's Manual of Systematic. Bacteriology. 2nd ed. New York.

[13] Atluri, V.L., Xavier, M.N., deJong, M.F., den Hartigh, A.B. and Tsolis, R.M. (2011). Interactions of the human pathogenic Brucella species with their hosts. Annu. Rev. Microbiol., 65: 523-541.

[14] Radostits, O.M., Gay, C.C., Blood, C.D. and Hinchcliff, K.W. (2000). Veterinary Medicine, Textbook of the Disease of Cattle, Sheep, Pigs, Goats and Horses. 9th edition. New York: W.B. Saunders Company Ltd, Pp. 867-882.

[15] Garin-Bastuji, B., Vaillant V., Albert D., Tourrand B., Danjean M.P., Lagier A., Rispal P., Benquet B., and Maurin M., De Valk H. and Mailles A. (2006). Is brucellosis due to the biovar 2 of Brucella Suisan emerging zoonosis in France Twocase reports in wild boar and hare hunters. In Proceedings of the International Society of Chemotherapy Disease Management Meeting, 1st International Meeting on Treatment of Human Brucellosis, 7-10 November, Ioannina, Greece.

[16] Lucero N.E., Ayala S.M., Escobar G.I. and Jacob N.R. (2008). Brucella isolated in humans and animals in Latin America from1968 to 2006. Epidemiol.Infect. 136:496-503.

[17] Alem,W. and Solomon, G. (2002). A retrospectivesero epidemiology study of Bovine Brucellosis in different production systems in Ethiopia. In Proceeding of $16^{\text {th }}$ ed.Annual Conference .Pp. 55-57.

[18] Gorvel, J. P. and Moreno E. (2002). Brucella intracellular life: from invasion to intracellular replication. Vet. Microbiol., 90: 281297.

[19] Young, E .J. (1995). An overview of human brucellosis. Clin. Infect. Dis., 21: 283-289.

[20] Glynn, M.K. and Lyn, T.V. (2008). Brucellosis. J. Am. Vet. Med. Assoc. 233: 900-908.

[21] Abdou, A.E. (2000). Fifty years of veterinary public health activities in the eastern Mediterranean region. Eastern Mediterranean Health Journal, 6: 796-807.

[22] CFSPH. (2009). Brucellosis (Undulant fever, Malta fever, Mediterranean fever, Enzootic Abortion, Epizootic Abortion, Contagious Abortion, Bangs disease). Center for Food Security and Public Health Iowa State University College of Veterinary Medicine .ww.cfsph.iastate.ed/IICAB. Pp., 1-13.

[23] Arellano Reynoso, B., Suárez-Güemes, F., Mejia, E.F., Michel Gómez, F., Hernández-Castro R., Belt ran, A.R. and DiazAparicio E. (2013). Isolation of a field strain of Brucella abortus from RB51 vaccinated and brucellosis-seronegative bovine yearlings that calved normally. Trop. Anim. Hlth Prod., 45: 695-697.
[24] Asmare, K., Asfaw, Y., Gelaye, E.andAyelet, G (2010) Brucellosis in extensive management system of Zebu cattle in Sidama Zone, Southern Ethiopia. Afr. J. Agric. Res.5, 257-263.

[25] Alem W, Solomon G (2002). A retrospective sero-epidemiology study of Bovine Brucellosis in different Production Systems in Ethiopia .In: Proceeding of 16th Annual Conference. pp 53-57. June 5-6, Addis Ababa, Ethiopia.

[26] Hotez, P., Savioli, L. and Fenwick, A. (2012). Neglected tropical diseases of the Middle East and North Africa: review of their prevalence, distribution, and opportunities for control. PLoSnegl. trop. Dis., 6:1475.

[27] Sharma, S., Alka, Mahajan V., Verma S., Kaur K., Meenakshi and Kumar H. (2007). Screening of dairy farms of Punjab (India) for brucellosis and Para tuberculosis. Indian Vet. J, 84: 315-316.

[28] Mangen, M.-J., Otte J., Pfeiffer D. and Chilonda P. (2002). Bovine brucellosis in sub-Saharan Africa: estimationofsero-prevalence and impact on meat and milk offtakepotential. Livestock Policy Discussion Paper No. 8. Food and Agriculture Organization of the United Nations (FAO) Livestock Information and Policy Branch, Rome.

[29] World Organization for Animal Health (OIE) (1987). Bovine brucellosis and brucellosis of small ruminants. OIE Technical Series, 6: 48-49.

[30] Ibrahim, N., Belihu, K., Lobago, F. and Bekana, M. (2010). Seroprevalence of bovine brucellosis and its risk factors in Jimma zone of Oromia region, South-western Ethiopia. Trop. Anim. Health Prod. 42: 35-40.

[31] Kebede T., Ejeta G. and Ameni G. (2008). Seroprevalence of bovine brucellosis in smallholder farms in central Ethiopia (Wuchale-Jida district). Rev. Méd. Vet., 159: 3-9.

[32] Asmare K., Prasad, S., Asfaw, Y., Gelaye, E., Ayelet, G. and Zeleke, A. (2007). Seroprevalence Of brucellosis in cattle and in high risk animal health professionals in Sidama Zone, Southern Ethiopia. Ethiop. Vet. J.11, 69-83.

[33] Hunduma, D. and C. Regassa (2009). Seroprevalence study of bovine brucellosis in pastoral and Agro- pastoral areas of east Showa zone, Oromia Regional State, Ethiopia. American-Eurasian J. Agri. Env. Sci., 6: 508-512.

[34] Megara, B., Biffa, D., Abunna, F., Regassa, A., Godfroid, J. and Skjerve, E., (2011). Seroprevalence of brucellosis and its contribution to abortion in cattle, camel, and goat kept under pastoral management in Borana, Ethiopia. Trop. Anim. Health Prod. 43: 651-656.

[35] Tekleye, B., Kassali O.B., Mugurewa M., Sholtens R.G. and Tamirat Y. (1989). The prevalence of brucellosis in indigenous cattle in central Ethiopia. Bull. Anim. Hlth Prod. Afr., 37: 97-98.

[36] Eshetu, Y., Kassahun J., Abebe P., Beyene M., Zewdie B. and Bekele A. (2005). Seroprevalence study of brucellosis in dairy cattle in Addis Ababa, Ethiopia. Bull. Anim. Hlth Prod. Afr., 53, 211-214.

[37] Tolosa, T., Regassa F. and Belihu K. (2008). Seroprevalence study of bovine brucellosis in extensive management systems in selected sites of Jimma zone, Western Ethiopia. Bull. Anim. Hlth Prod. Afr., 56: 25-37.

[38] Mangen MJ, Otte J, Pfeiffer D, Chilonda P (2002). Bovine brucellosis in sub-Saharan Africa: estimation of sero-prevalence and impact on meat and milk off take potential. Livestock Policy Discussion Paper No. 8 Rome: Food and Agriculture of the United Nations - Livestock Information and Policy Branch, AGAL. P. 58.

[39] Adugna, G.E., and Alga G. (2013). Seroepidemiological survey of bovine brucellosis in cattle under a traditional production system in western Ethiopia. Rev Sci Tech. 2013 Dec; 32(3): 765-73.

[40] Sintayehu G, Melesse B, Abayneh D, Sintayehu A, Melaku S, Alehegne W, Mesfin S, De Blas I, Casal J, Allepuz A, MartinValls G, Africa T and Abera K.(2015). Epidemiological survey of brucellosis in sheep and goats in selected pastoral and agropastoral lowlands of Ethiopia. Rev Sci Tech.34: 881-93.

[41] Waring, S. C. (2005). Brucellosis. In: Kahn CM, Line S, eds. Merck Veterinary Manual. $9^{\text {th }} e d$. Whitehouse Station, New Jersy, USA.

[42] Seifert, S.H. (1996). Tropical Animal Health.2nd edition. Dordrechet: Kluwer Academic Publishers P. 358.

[43] Walker, R.L. (1999). Brucella. In: Dwight C. Hirsh and Yuang Chung Zee (ED.): Veterinary Microbiology. USA: Blackwell Science Inc. Pp. 196-203.

[44] World organization for Animal Health (OIE) (2010). Bovine brucellosis, Chapter 2.4.3. [Version adopted by the World 
Assembly of Delegates of the OIE in May 2009]. In Manual of Diagnostic Tests and Vaccines for Terrestrial Animals. OIE, Paris. Available at: www.oie.int/fi leadmin/Home/eng/Health_ standards/tahm/2.04.03_bovine_brucell.pdf (accessed on13 March 2017).

[45] World Organization for Animal Health (OIE) (2008). 59-63. Bovinebrucellosis.InManual of diagnostic tests and vaccines for terrestrial animals. Available at: www.oie.int/en/internationalstandard-setting/terrestrialmanual/access-online/ (accessed on 1 March 2017.

[46] World Organization for Animal Health (OIE) (2004). Manual of diagnostic tests and vaccines for terrestrial animals, 5th Ed.OIE, Paris, France.

[47] Colmenero, J.D., Morata P., Ruiz-Mes,a J.D., Bautista D., Bermúdez, P., Bravo, M.J., and Queipo-Ortuño, M.I., (2010). Multiplex real-time polymerase chain reaction: a practical approach for rapid diagnosis of tuberculosis and Brucella vertebral osteomyelitis. Spine, 35: 1392-1396.

[48] Queipo-Ortuño, M.I., Colmenero J.D., Macias M., Bravo M.J. and Morata P. (2008). Preparation of bacterial DNA template by boiling and effect of immunoglobulin $\mathrm{G}$ as an inhibitor in real time PCR for serum samples from patients with brucellosis. Clin. Vaccine Immunol.15: 293-296.

[49] Ariza, J, Gudio, l F, Pallarés, R, Rufi, G. and Fernàndez- Viladrich, P. (1985). Comparative trial of rifampicin-doxycycline versus tetracycline-streptomycin in the therapy of human brucellosis. Antimicrobial Agents Chemother, 28:548-51.

[50] Joint FAO/WHO. (1986). Expert Committee on Brucellosis. Sixth Report. World Health Organ Tech Rep Ser No.740. Geneva, Switzerland.

[51] Barrio, M.B., Grilló, M.J., Muñoz, P.M., Jacques, I., González, D de Miguel, M.J., Marin, C.M., Barberán M., Letesson J.J., Gorvel, J.P., Moriyón, I., Blasco, J.M. and Zygmunt, M.S. (2009). Rough mutants defective in core and O-polysaccharide synthesis and export induce antibodies reacting in an indirect ELISA with smooth lipopolysaccharide and are less effective than Rev 1 vaccine against Brucella melitensis infection of sheep. Vaccine, 27: 1741-1749.

[52] Schiffman, J, Beer T, Yonghong W (2002). The emergence of global disease 7-882 control priorities. Health Policy and Planning, 17: 225-234.

[53] Yohannes M., Degefu, H., Tolosa, T., Belihu, K., Cutler, R and Cutler, S.(2013). Brucellosis in Ethiopia. African J. Microbiol, 7: 1154-1155.

[54] Thakur, S.D. and Thapliyal D.C. (2002). Seroprevalence of brucellosis in man. J. Commun. Dis., 34:106-109.

[55] Bertu, W.J., Gusi, A.M., Hassan, M., Mwankon, E., Ocholi, R.A., Io,r D.D., Husseini, B.A., Ibrahim, G., Abdoel, T.H. and Smits, H.L. (2012). Serological evidence for brucellosis in Bos indicus in Nigeria. Trop. Anim. Health Prod. 44: 253-258.

[56] Ward, D., Jackson, R., Karomatullo, H., Khakimov, T., Kurbonov, K., Amirbekov, M., Stack, J., El-Idrissi, A. and Heuer, C. (2012). Brucellosis control in Tajikistan using Rev 1 vaccine: change in seroprevalence in small ruminants from 2004 to 2009. Vet Rec. 2012 Jan; 170 (4):100.

[57] Cheville,N.F., Olsen, S.C, Jensen, A.E, Stevens, MG, Palmer, M.V. and Florance, A.M., (1996). Effects of age at vaccination on efficacy of Brucella abortus strain RB51 to protect cattle against brucellosis. Am. J. Vet. Res. 57: 1153-1156.

[58] Skalsky, K., Yahav D., Bishara J., Pitlik S., Lelbovici L. and Paul M (2008). Treatment of human brucellosis: systematic review and meta-analysis of randomized controlled trials. Br. Med. J. 336: 701-704.

[59] Muendo, E.N., Mbatha, P.M., Macharia, J., Abdoel, T.H., Janszen, P.V, Pastoor, R. and Smits, H.L. (2012). Infection of cattle in
Kenya with Brucella abortus biovar 3 and Brucella melitensis biovar 1 genotypes. Trop. Anim. Health Prod. 44: 17-20.

[60] W.H.O. (1986). Joint FAO/ WHO Committee on brucellosis. 6th Report. Technical Report Series, No.740. World Health Organization, Geneva, Switzerland.

[61] Robinson, A. (2003). Guidelines for coordinated human and animal brucellosis surveillance. Food and Agriculture Organization of the United Nations, Rome. Available at: www. fao.org/docrep/006/y4723e/y4723e0e.htm (accessed in July2011).

[62] OIE (2009). Bovine brucellosis.OIE, Paris, France. http://www.oie.int/fileadmin/Home/eng/Health_standards/tahm/20 08/pdf/2.04.03_BOVINE_BRUCELL.pdf

[63] Godfroid, J., Garin-Bastuji B., Saegerman,C. and Blasco, J.M. (2013). Brucellosis in terrestrial wildlife. In Brucellosis recent developments towards One Health (G.E. Plumbs'.Olsen \& G. Pappas, Eds). Rev. Sci. tech. Off. int. Epiz. 32:27-42.

[64] Dahouk, A.l S., Sprague, L.D. and Nuebauer, H. (2013). New developments in the diagnostic procedures of zoonotic brucellosis. In Brucellosis recent developments towards One Health (G.E. Plumb, S.C. Olsen \& G. Pappas, Eds). Rev. Sci. tech. Off. Int. Epiz 32: 177-188.

[65] Poester, F.P. Samartino L.E. and Santos R.L. (2013). Pathogenesis and pathobiology of brucellosis in livestock. InBrucellosis: recent developments towards One Health (G.E. Plumb, S.C. Olsen \& G. Pappas, eds). Rev. Sci. tech. Off.int. Epiz, 32: 105-115.

[66] Chugh, T.D. (2008). Emerging and re-emerging bacterial diseases in India. J. Biosci., 33, 549-555.

[67] Cutler, S. and Whatmore, A. (2003). Progress understanding brucellosis. Vet. Rec. 153:641-642.

[68] Pappas, G., Papadimitriou, P, Akritidis, N., Christou, L. and Tsianos, E. (2006). The new global map of human brucellosis. Lancet Infect. Dis. 6:91-99.

[69] Tolosa, T., Ragassa F., Belihy K., and Tizazu G. (2007). Brucellosis among patients with fever of unknown origin in Jimma University Hospital South Western Ethiopia. Ethiop. J. Health Sci., 7: 1153-1154.

[70] Ragassa, G., Mekonnen, D, Yamuah, L., Tilahun, H., Guta, T., Gebreyohannes, A., Aseffa, A., Abdoel, T.H. and Smits, H.L. (2009). Human brucellosis in Traditional pastoral communities in Ethiopia. Int. J. Trop. Med. 4:59-64.

[71] Mussie, H., Tesfu K. and Yilkal, A. (2007). Seroprevalence study of bovine brucellosis in Bahir Dar Milk shed, Northwestern Amhara Region. Ethiop. Vet. J. 11:42-49.

[72] Kassahun, A., Shiv, P., Yilkal, A., Esayas, G., Gelagaye, A. and Aschalew, Z. (2007). Seroprevalence of brucellosis in cattle and high risk professionals in Sidama Zone, Southern Ethiopia. Ethiop. Vet. J. 11: 69-84.

[73] Kassahun, J., Yimer, E., Geyid, A., Abebe, P., Newayeselassie, B., Zewdie, B, and Beyene, M. and Bekele, A (2006). Seroprevalence of brucellosis in occupationally exposed people in Addis Ababa, Ethiopia.

[74] Madkour, M.M. (2001). Osteoarticularbrucellosis. In Madkour's brucellosis (M.M. Madkour, ed.), 2nd Ed. Springer-Verlag, Berlin-Heidelberg, Pp.74-84.

[75] McDermott and Grace D. (2012). Agriculture-associated diseases: adapting agriculture to improve human health. In reshaping agriculture for nutrition and health (S. Fan and R. Pandya-Lorch, eds). International Food Policy Research Institute, Washington, DC, Pp. 103-111.

[76] McDermott, J., Grace, D. and Zinsstag, J. (2013). Economics of brucellosis impactand control in low-income countries, Rev. Sci. Tech. J., 32: 249-261.

[77] Zamri-Saad, M and Kamarudin, M.I. (2016). Control of animal brucellosis: The Malaysian experience. Asian Pac. J. Trop. Med. 9:1136-1140. 